\title{
Discussion to paper of Dr Jurascheck et al.
}

\section{Chairman: DR HACHEN}

DR MADERSBACHER (Austria). I thank you very much for this interesting paper because I think at first when the urologists started dealing with neurogenic bladders they only focussed on the bladder. Then there was the time when they were only focussed on the bladder outlet doing sphincterotomy doing pharmacotherapy. I think it is your paper that has brought us back to realise that there still exists also a detrusor which has to drive out urine and that the position of the bladder and detrusor contraction are also influencing micturition.

Dr Perkash (U.S.A.). I have had several patients who can void very well when they are lying with the bladder falling back, whereas when they sit up with a loose relaxed abdominal wall then the bladder tends to sort of override the pubic symphisis. Those factors are to be appreciated in these patients. Of course, you can go ahead and do a little more sphincterotomy or cut the bladder neck and sometimes you can improve the voiding; or give them an abdominal corset so that before they get out of bed they are wearing an abdominal binder and their voiding is improved.

Chairman. Dr Jurascheck will present a few interesting slides and Dr Dollfus will make the comments to them.

DR P. Dollfus (France). Here is a paraplegic whose micturition is produced in two different ways, one by percussion, by abdominal straining and you can see the way that the whole anterior part of the prostate has gone down, pressing backwards into the canal and obstructing the canal. patient.

DR MINAIRE (France). I would like to know the neurological level of this paraplegic

Dr Dollfus. TiI/Ti2 complete.

DR MADERSBACHER. Colocystopexy. Have you any troubles with defecation after this operation.

DR Dollfus. The colocystopexy is a technique used by Dr Archimbaud in Lyons.

DR MINAIRE. Archimbaud is our urologist in Lyons and he described the procedure. It is true that we have some problem with defecation in some patients. I have seen personally 8 cases treated and they have had 6 months sometimes 12 months disimbalance of the defecation. You have to check carefully the defecation and you can obtain a new balance after maybe 6 or I2 months.

Dr MADERSBACHer. Dr Dollfus showed in two slides how to fix a bladder in order to avoid its coming down and as we have had problems with defecation with colocystopaxy do you prefer now only the anterior prostatocystopaxy?

DR Dollfus. Dr Jurascheck only does an anterior one and closes the Douglas pouch if necessary. 